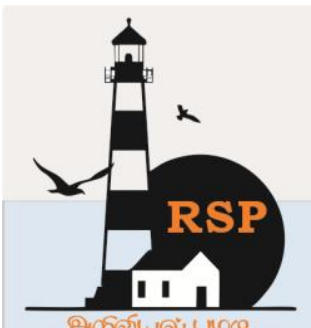

INTERNATIONAL RESEARCH JOURNAL ON ADVANCED SCIENCE HUB

Open Access
Open $2582-4376$

RSP SCIENCE HUB

(The Hub of Research Ideas)

Available online at www.rspsciencehub.com

\title{
Design and Fabrication of Fixture for Rotary and Vertical Welding
}

Vetrivel $A^{1}$, Raguram $G^{2}$, Ramprakash $R^{3}{ }^{3}$, Rohidh $S^{4}$, Sri Hari $T^{5}$

${ }^{1}$ Assistant Professor, Department of Mechanical Engineering, SNS College of Technology, Coimbatore641035, Tamilnadu, India.

${ }^{2,3,4,5}$ Student, Department of Mechanical Engineering, SNS College of Technology, Coimbatore-641035, Tamilnadu, India. raguramgunasekaran@gmail.com ${ }^{2}$

\section{Abstract}

This project is to fabricate a fixture which can be used to revolve and reciprocate the work piece for welding of cylindrical components. Typically, a welding of a cylindrical component involves rotating a large fixture mounted horizontally and the welding head performs the welding by moving in the horizontal axis. The drawbacks of this method are that it damages the welding cable upon the motion and the use of complex electrode feeding systems. This fixture eliminates those complications by making the welding components static and mounting the welding head stationary at a required angle for the operation. A Stepper motor rotates the circular fixture which is used to clamp the cylindrical work piece. The vertical movement is carried out by the screw rod which is used to rotate the fixture. This gives a cost-effective way to have good quality welded material and gives a standard weld seam in the process than the irregular seam due to human error in the conventional process. The vertical movement is carried out by the actuation of the lead screw which consists of screw in a screw nut which is fixed on the base plate. One end of the screw is connected to the handle for actuation and the other end is welded to the fixture plate. Upon rotating the handle, the lead screw starts to rotate and move up at the same time due to screw action. Thus, making the Fixture to revolve and reciprocate at the same time to weld the component vertically.

\section{Keywords: Welding, lead screw, fixture, cylindrical work piece}

\section{Introduction to Welding}

Welding is a manufacturing process employed in the fabrication of metals and plastics by heating them to its melting point and joining them. Jigs and fixtures are used to hold the work piece for any kind of manufacturing process. As in welding fixtures play an important part of holding the workpiece as they get welded. When it comes to Longitudinal and circular seam welding the fixture should hold the workpiece when it moves longitudinally and axially. So, we designed a fixture along with lead screw mechanism in order to move the work piece based on the type of welding while keeping the welding electrodes stationary to ease the complexity in welding process.

\section{Summary of Literature Review}

From the above literature's we can know that the rotating and linear motion can achieved by many different possible ways. The simple and efficient possible way that can be cost effective and productive in terms of quantity is by having simple 
mechanism is using lead screw method. The lead method one the simple method used for linear and rotating motion. The alternate method incorporated for automatic and high-end model is having the stepper motor which can used for reciprocating motion in vertical direction this method is one of the effective ways for producing rapid and quality product. The production cycle and timing can be monitored and programmed as per requirement and demand needs.

\section{Construction for Rotary and Linear Fixture}

This prototype is generally for components generally below 3" this can be manufactured for higher size with higher specification in larger scale for different operating specifications. The process of a Spiral, Longitudinal and Circular welding involves a fixture or the electrode to rotate and move in a linear fashion to perform welding. Which is difficult for each and every detail to be resolved in the work piece this can lead to product being incomplete or with defect in the welding process being carried out? The human error rate can be high enough for having poor product in the market. The efficient way to carry out this process is to make a Rotary and Linear Fixture that can do both by using screw transmission. The method of bringing this screw transmission can have good result in having the quality product. This screw transmission is generally carried out by the method of transmission of screw in linear and rotary motion is by having a lead screw and its nut being welded with the rectangular plate at the top of the support which is holding the rectangular plate this give the stable movement for the lead screw for linear and rotary transmission the circular plate welding at the top of the lead screw for having the work piece mounted at the top of the lead screw and through which linear and rotary motion can transferred successfully. Thus, making the prototype ready for testing and manufacturing in large scale.

\section{Working Principle}

The working of fixture is as simple as the mechanism used in the process. When the screw is rotated in any direction using the handrail which is incorporated for cost effective mechanism in the manufacturing of fixture. The fixture is all set and ready for operating after assembly. When the handrail is operated the screw is rotated where rotary motion and linear motion is simultaneously carried away this helps the 360 degree for effective work without any deviation in the procedure in natural welding process. This rotational and linear movement is carefully calculated with pitch and length to be welded according the product description can be operated at different diameter with different circular plate attached to the lead screw. The lead screw which is calculated with load which it can withstand.Thus, providing wide range of different and more reliable machine which can be adjusted to any diameter for any required needs.

\section{Design and Analysis of Fixture}

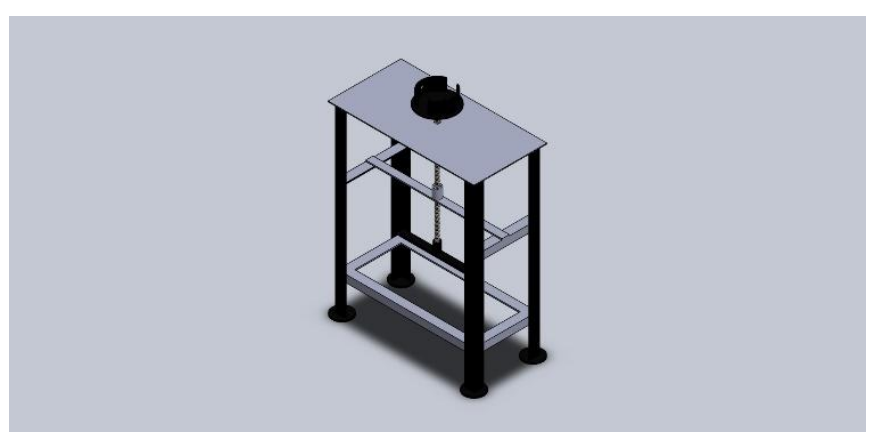

Fig.1. Fixture for Rotary and Vertical Welding

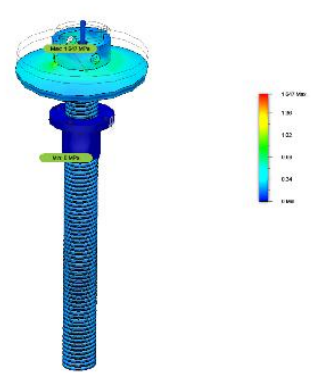

Fig.2. Stress Analysis

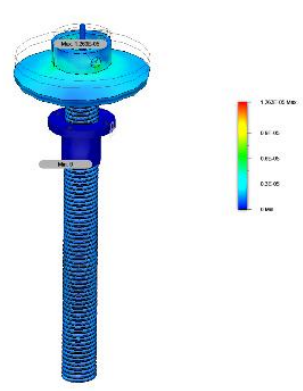

Fig.3. Strain Analysis 


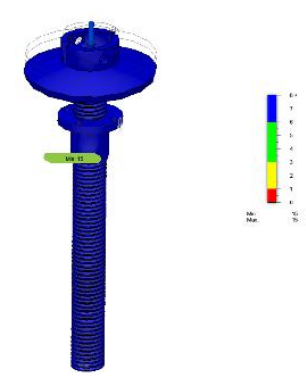

Fig.4. Safety Factor

\section{Calculations}

\section{Screw rod:}

Diameter of the screw $=20 \mathrm{~mm}$, Height of the screw $=500 \mathrm{~mm}$

Mild steel density $=7850 \mathrm{~kg} / \mathrm{m}^{3}$

Volume of the screw $=\pi r^{2} h$

$$
\begin{aligned}
& =3.14 \times 10^{2} \times 500 \\
& =157000 \mathrm{~mm}^{3} \\
& =0.000157 \mathrm{~m}^{3}
\end{aligned}
$$

Mass of the screw $=0.000157 \times 7850$

$$
=1.23 \mathrm{~kg}
$$

Weight of the screw $=12 \mathrm{~N}$

\section{Bearing:}

Mass of the bearing $=0.205 \mathrm{~kg}$

Weight of the bearing $=2 \mathrm{~N}$

\section{Fixture:}

Diameter of the circular plate $=152.4 \mathrm{~mm}$, Thickness $=5 \mathrm{~mm}$

Mild steel density $=7850 \mathrm{~kg} / \mathrm{m}^{3}$

Volume of the fixture $=\pi r^{2} h$

$$
\begin{aligned}
& =3.14 \times 76.2^{2} \times 5 \\
& =9.11 \times 10^{-5} \mathrm{~m}^{3}
\end{aligned}
$$

Mass of the fixture $=9.11 \times 10^{-5} \times 7850$

$$
=0.715 \mathrm{~kg}
$$

Weight of the fixture $=7 \mathrm{~N}$

\section{Workpiece:}

Outer diameter $=82.2 \mathrm{~mm}$, Internal diameter $=$ $76.2 \mathrm{~mm}$, Height of the pipe $=500 \mathrm{~mm}$

Mild steel density $=7850 \mathrm{~kg} / \mathrm{m}^{3}$

Volume of the pipe $=\pi \mathrm{h}\left(\mathrm{r}_{1}{ }^{2}-\mathrm{r}_{2}^{2)}\right.$

$$
\begin{gathered}
=3.14 \times 500\left[(41.1)^{2}-(38.1)^{2}\right] \\
=0.000373 \mathrm{~m}^{3}
\end{gathered}
$$

Mass of the pipe $=0.000373 \times 7850$

$$
=2.93 \mathrm{~kg}
$$

Weight of the pipe $=28.74 \mathrm{~N}$

Total load:

Total load

$$
\begin{aligned}
& =12+2+7+28.74 \\
& =49.74
\end{aligned}
$$

Total load $\approx 50 \mathrm{~N}$

\section{Torque:}

Length of the handle $(\perp$ distance $)=20 \mathrm{~cm}$

Torque required to rotate the fixture $=$ Total load $x$ Perpendicular distance

$$
\begin{aligned}
& =50 \times 20 \\
& =1000 \mathrm{~N} \mathrm{~cm}
\end{aligned}
$$

\section{Conclusions}

Thus, from this project we have developed a fixture for rotary and vertical welding in which the work piece rotates and moves vertically and the electrode remains stationary in order to avoid damages in the electrode when it rotates and moves. Linear screw actuation is used to make the fixture rotate and move vertically as the work piece is fixed in it. This fixture can seam weld work pieces in a longitudinal and circular fashion and can be altered to produce spiral welding. The fixture is used to make longitudinal and circular welds in a pipe which used in construction, Petro chemical, power plants and irrigation systems.

\section{References \\ Patent}

[1] US2749421A - Welding head positioner Google Patents 1954

[2] US4595186A - Rotating welding fixture Google Patents 1984

[3] US3596898A - Fixture for welding pipes Google Patents 1969

[4] US4804813A - Welding device for a cylindrical tube - Google Patents 1988

[5] "Automatic design of fixtures for machining processes" by Yon-Chun Chou 2011. 